\begin{tabular}{lc}
\hline JOURNAL OF SCIENTIFIC PERSPECTIVES \\
RAADEMY \\
E-ISSN: $2587-3008$ \\
Attpril//ratingacademy.com.tr/journals/index.php/jsp/ 2018, Vol:2, Issue: 2 \\
\hline
\end{tabular}

\title{
STABILITY OF METAL OXIDE SUSPENSION IN THE CATIONIC POL YACRYLAMIDE PRESENCE
}

\author{
Assoc. Prof. Dr. Malgortza WIŚNIEWSKA, \\ E-mail:wisniewska@hektor.umcs.lublin.pl \\ Prof. Dr. Stanislaw CHIBOWSKI \\ Dr. Teresa URBAN ${ }^{a}$ \\ Mgr. Gracja FIJALKOWSKA ${ }^{a}$ \\ ${ }^{b}$ Department of Radiochemistry and Colloids Chemistry, Faculty of Chemistry, Maria Curie- \\ SklodowskaUniversity, Maria Curie-Sklodowska Sq. 3, 20-031 Lublin, Poland,: \\ Assoc. Prof. Dr. Agnieszka NOSAL-WIERCINSKA ${ }^{b}$ \\ ${ }^{b}$ Department of Analytical Chemistry and Instrumental Analysis, Faculty of Chemistry, Maria Curie- \\ Sklodowska University, Maria Curie-Sklodowska Sq. 3, 20-031 Lublin, Poland \\ Assoc. Prof. Dr. Gulsen SAGLIKOGLU \\ Canakkale Onsekiz Mart University, Faculty of Science and Arts, Department of Chemistry, \\ Canakkale, Turkey \\ Assoc. Prof. Dr. Murat SADIKOGLU \\ Gaziosmanpasa University, Faculty of Education, Department of Science Education, Tokat, Turkey \\ Prof. Dr. Selehattin YILMAZ* \\ Canakkale Onsekiz Mart University, Faculty of Science and Arts, Department of Chemistry, \\ Canakkale,Turkey,E-mail:seletyilmaz@hotmail.com

\begin{tabular}{|c|c|}
\hline ARTICLE INFO & ABSTRACT \\
\hline $\begin{array}{l}\text { Article History: } \\
\text { Received: } 28 \text { Marc } \\
\text { Accepted: } 04 \text { April }\end{array}$ & \multirow{3}{*}{$\begin{array}{l}\text { In this study, electroanalytical technique was developed for the quantitative } \\
\text { analysis of clomipramine hydrochloride from its commercial tablet dosage forms } \\
\text { based on its oxidation behavior. The electrochemical determination of } \\
\text { clomipramine hydrochloride was easily carried out on glassy carbon electrode } \\
\text { (GCE) by two voltammetric techniques. The electrochemical measurements were } \\
\text { carried out on GCE surface in different buffer solutions in the pH range from } 2.00 \\
\text { to } 12.00 \text { by cyclic voltammetry (CV) and differential pulse voltammetry (DPV) } \\
\text { techniques. The effect of pH on the anodic peak current and peak potential was } \\
\text { investigated. Phosphate buffer ( } p H \text { 6.50) was selected for analytical purposes. } \\
\text { The diffusion-controlled nature of the peak was obtained. A linear calibration } \\
\text { plot for DPV analysis was constructed in the clozapine concentration range from } \\
5 \times 10^{-6} \text { mol } L^{-1} \text { to } 3 \times 10^{-5} \text { mol } L^{-1} \text {. Limit of detection (LOD) and limit of } \\
\text { quantification (LOQ) were obtained as } 2.8 \times 10^{-7} \mathrm{~mol}^{-1} \text { and } 8.4 \times 10^{-7} \text { mol } L^{-1} \\
\text { respectively. }\end{array}$} \\
\hline $\begin{array}{l}\text { Keywords: } \\
\text { cationic pol } \\
\text { electrokinet } \\
\text { suspension } \\
\text { adsorption. }\end{array}$ & \\
\hline DOI: 10.2 & \\
\hline
\end{tabular}




\section{INTRODUCTION}

The main reaction of cationic polyacrylamide (PAM) synthesis is free radical copolymerization of acrylamide with the cationic monomer (Jiang and Zhu, 2014). The monomer containing positively charged functional groups used for synthesis of polymer applied in this study is dimethyldiallyl ammonium chloride (DMDAAC). As a result, the quaternary amine groups are introduced to the macromolecules. Contrary to polymer amide groups, these amine groups undergo ionization in aqueous solutions with the changes in solution $\mathrm{pH}$ value and are the source of positive charge of polymeric chains.

The most important field of cationic polyacrylamide application is the flocculation process of undesirable solids characterized by high dispersion in aqueous solutions. Long polymeric chains (with molecular weight of the order of several and dozen million Daltons) have ability to form polymeric bridges between the solid particles and their effective aggregation (easily sediment flocs are formed). Moreover, PAM is widely used in removal of polyvalent metal ions, organic compounds (i.e. dyes) and microorganisms from aqueous solutions. For such reasons ionic polyacrylamide finds application in the procedures of industrial waste water purification and drinking water treatment (Entry and Sojka 2000, Amuda et al. 2006, Barakat 2011). Cationic polyacrylamide is also used as the rain erosion control agent is agriculture (Sojka et al. 2007). By binding loose solid particles the polymer improves considerably the consistency of the soil (simultaneously maintaining surface roughness and continuity of pores).

Thus, such long polymeric chains containing charged functional groups are effective modifiers of the surface properties of solid particles dispersed in liquid medium. The specific structure of polymeric layers covering colloidal particles determines directly such systems stability.

Suspensions of metal oxides are colloidal systems very often encountered in practice. Metal oxides play an important role in adsorptive removal of a great variety of hazardous substances (Wawrzkiewicz et al. 2015). They are also used in production of cosmetics, pharmaceuticals and mineral pigments (Simpson et al. 2011, Vargas-Reus et al. 2012). To obtain the required surface properties of metal oxide particles they were often modified by adsorbed polymers. The specific conformation of polymer chains adsorbed at the solid-liquid interface can be obtained by appropriate selection of among others polymer kind (ionic, nonionic) and metal oxide type, temperature, solution $\mathrm{pH}$, as well as supporting electrolyte type and its concentration (Wiśniewska 2012).

The main aim of studies presented in the manuscript was comparison of stability of three selected metal oxides suspensions (chromium(III) oxide $-\mathrm{Cr}_{2} \mathrm{O}_{3}$, zirconium(IV) oxide $-\mathrm{ZrO}_{2}$ (zirconia) and aluminum(III) oxide $-\mathrm{Al}_{2} \mathrm{O}_{3}$ (alumina) in the presence of cationic polyacrylamide (PAM). The obtained changes in these systems stability (turbidimetry method) after polymer addition were explained based on the analysis of adsorption (spectrophotometry method), surface charge density of the solid (potentiometric titrations) and zeta potential of metal oxide particles (laser microelectrophoresis technique) data.

\section{MATERIAL AND METHODS}

\subsection{Adsorption system characteristics}

In the experiments three metal oxides were used as adsorbents - chromium(III) oxide: $\mathrm{Cr}_{2} \mathrm{O}_{3}$ (POCh), zirconium(IV) oxide: $\mathrm{ZrO}_{2}$ (Sigma-Aldrich) and aluminium(III) oxide: $\mathrm{Al}_{2} \mathrm{O}_{3}$ (Merck). They were characterized by the specific surface area ( $\left.\mathrm{S}_{\mathrm{BET}}\right)$ equal to: 7.12, 21.7 and 
$155 \mathrm{~m}^{2} / \mathrm{g}$, respectively. $\mathrm{S}_{\mathrm{BET}}$ was determined using the low-temperature nitrogen adsorptiondesorption isotherm method (Micrometritics ASAP 2405 Analyzer).

The cationic polyacrylamide - PAM (Korona) with the weight average molecular weight $7000000 \mathrm{Da}$ and the content of quaternary amine groups $50 \%$ was applied as an adsorbate (Fig. 1). The $\mathrm{pK}_{\mathrm{b}}$ value of this polymer is equal to 9.9 and was determined using the potentiometric titration method. Knowing $\mathrm{pK}_{\mathrm{b}}$ value, the ionization degree $(\alpha)$ of the PAM cationic groups can be calculated (Wiśniewska et al. 2015). At pH $3 \alpha=99.9 \%$, at $\mathrm{pH} 6$ it assumes the value $99.9 \%$, whereas at $\mathrm{pH} 9$ the ionization degree is equal to $88.8 \%$.

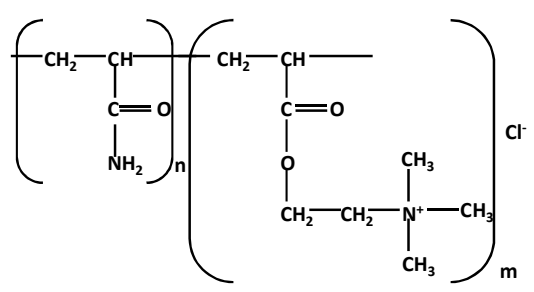

Figure 1. Chemical formula of cationic polyacrylamide.

All measurements were made in the $\mathrm{pH}$ range $3-9$ at $25^{\circ} \mathrm{C}$ in the presence of $\mathrm{NaCl}$ (as supporting electrolyte) with the concentration $1 \cdot 10^{-2} \mathrm{~mol} / \mathrm{dm}^{3}$.

\subsection{Stability measurements}

The stability measurements of metal oxide suspensions in the absence and presence of PAM were performed using the turbidimetry method (Terpiłowski et al. 2015). For this purpose, the apparatus Turbiscan Lab ${ }^{\text {Expert }}$ with the cooling module TLAb cooler (Formulaction, France) was applied. The suspension of $0.2 \mathrm{~g}$ of oxide in $20 \mathrm{~cm}^{3}$ of $\mathrm{NaCl}$ solution (or PAM-NaCl, CPAM 100 ppm) was prepared. Each experiment of suspension stability lasted $15 \mathrm{~h}$ and every $15 \mathrm{~min}$ the respective data (light transmission and backscattering level) were collected. TLab EXPERT 1.13 and Turbiscan Easy Soft computer programs enabled calculations of stability coefficients TSI (Turbiscan Stability Index). The limit values of TSI are 0 (very stable suspensions) and 100 (extremely unstable systems). Moreover, knowing the aggregate migration velocity (on the basis of the changes of transmission or backscattering in time), the aggregate size was calculated using the general law of sedimentation - Stokes law extended on concentrated dispersions (Snabre and Mills 1994).

\subsection{Adsorption measurements}

Adsorption measurements were performed using the static method in the polymer concentration range $10-150 \mathrm{ppm}$. The reaction of cationic polyacrylamide with a saturated solution of bromine, sodium formate and starch (in acetate buffer) (Scoggins and Miller 1975) was applied. It enables determination of the polyacrylamide concentration in the solution after the adsorption process (equilibrium concentration). The formed complex gives blue colour of the solution of different intensity depending on the polymer concentration. The solution absorbance was measured after 5 min with the UV-VIS spectrophotometer (Carry 1000; Varian) at $585 \mathrm{~nm}$. Using the calibration curve, the amount of the adsorbed polymer (in unit's $\mathrm{mg} / \mathrm{m} 2$ and $\mathrm{mg} / \mathrm{g}$ ) was determined from the difference between the PAM concentration in the solution before and after the adsorption process. 


\subsection{Solid surface charge density determination}

The potentiometric titration method (Janusz 1999) was used for the solid surface charge density determination. The appropriate mass of metal oxide was added into the thermostated (thermostat RE204, Lauda) Teflon vessel containing $50 \mathrm{~cm}^{3}$ of polymer solution (100 ppm) in the $\mathrm{NaCl}$ electrolyte (or only to $\mathrm{NaCl}$ electrolyte solution). Such systems were titrated with base $\mathrm{NaOH}$ with the concentration $1 \cdot 10^{-1} \mathrm{~mol} / \mathrm{dm}^{3}$ using the automatic burette Dosimat 665 (Methrom). The changes in the $\mathrm{pH}$ values during titration were monitored with the $\mathrm{pH}-\mathrm{meter}$ $71 \mathrm{pHmeter}$ (Beckman). The special program Titr_v3 (author W. Janusz) was applied to solid surface charge density calculation from the difference in the base volume added to the suspension and the supporting electrolyte solution that leads to the specific $\mathrm{pH}$ value. These measurements enable also determination of point of zero charge (pzc) values for all examined systems.

\subsection{Zeta potential determination}

The electrophoretic mobility of metal oxide particles (without and covered with polymer) was measured using the Zetasizer Nano ZS with the universal dip cell and MPT-2 titrator (Malvern Instruments). The Doppler laser electrophoresis technique was applied and the zeta potential value was calculated with the special computer program using the Henry equation (Hunter 1981). Metal oxide suspensions (without and with PAM) were prepared adding appropriate mass of the solid to $100 \mathrm{~cm}^{3}$ of $\mathrm{NaCl}$ solution or PAM-NaCl solution (polymer concentration $10 \mathrm{ppm}$ ). After the sonification process the obtained suspension was divided into 6 parts of the same volume. Then in each of them the $\mathrm{pH}$ value was adjusted to: 3 , $4.5,5.5,6.5,8.5$ and $10 \pm 0.1$, respectively and their electrophoretic mobility were measured. The values of isoelectric points (iep) of metal oxides were determined from obtained curves presenting dependencies of zeta potential as a function of solution $\mathrm{pH}$.

\section{RESULTS AND DISCUSSION}

As can be seen in Fig. 2 cationic polymer has the great impact on the metal oxide suspension stability at $\mathrm{pH} 6$.

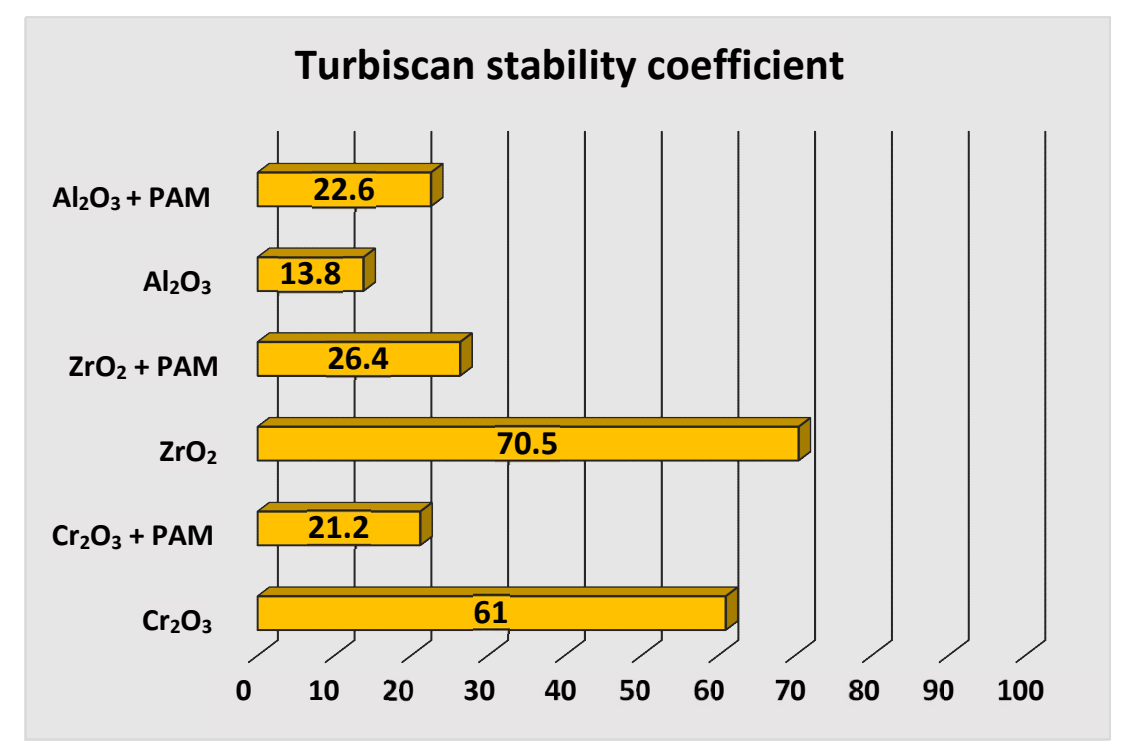

Figure 2. TSI stability coefficients of the metal oxide suspension without and with polyacrylamide at $\mathrm{pH} 6$. 


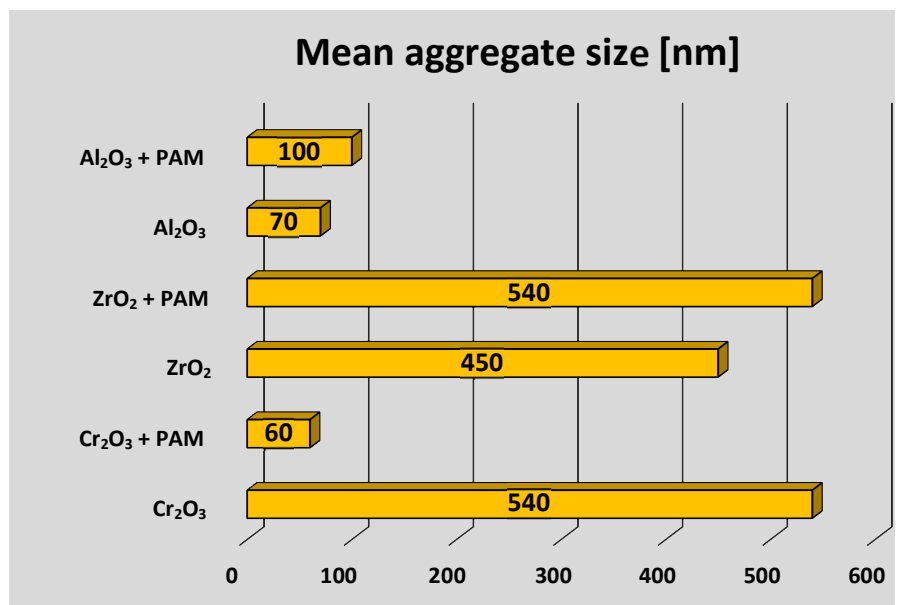

Figure 3. Mean aggregate sizes formed in the metal oxide suspension without and with polyacrylamide at $\mathrm{pH} 6$.

In the case of $\mathrm{Cr}_{2} \mathrm{O}_{3}, \mathrm{ZrO}_{2}$ systems without PAM and $\mathrm{ZrO}_{2}$ system with PAM, the suspensions are unstable (high TSI values) and large aggregates are formed - sizes in the range $450 \mathrm{~nm}-540 \mathrm{~nm}$, respectively, for chromium(III) oxide and zirconium(IV) oxide (Fig. 3). The polymer addition causes considerable improvement of stability conditions in these systems (TSI values decrease). In the case of $\mathrm{Al}_{2} \mathrm{O}_{3}$, suspension without cationic PAM is relatively stable and in the polymer presence insignificant decrease of its stability is observed. This is reflected in much smaller sizes of formed aggregates - not exceeding $100 \mathrm{~nm}$ (Fig. 3).

In order to explain the obtained changes in solid suspension stability after cationic polyacrylamide addition the analysis of adsorption and electrokinetic results is necessary. Figure 4 presents the PAM adsorbed amounts on the surfaces of applied metal oxides expressed in $\mathrm{mg} / \mathrm{m}^{2}$ (polymer/metal oxide surface, Fig.4a) and mg/g (polymer/metal oxide mass, Fig.4b), examined at three solution $\mathrm{pH}$ values.

\section{a}

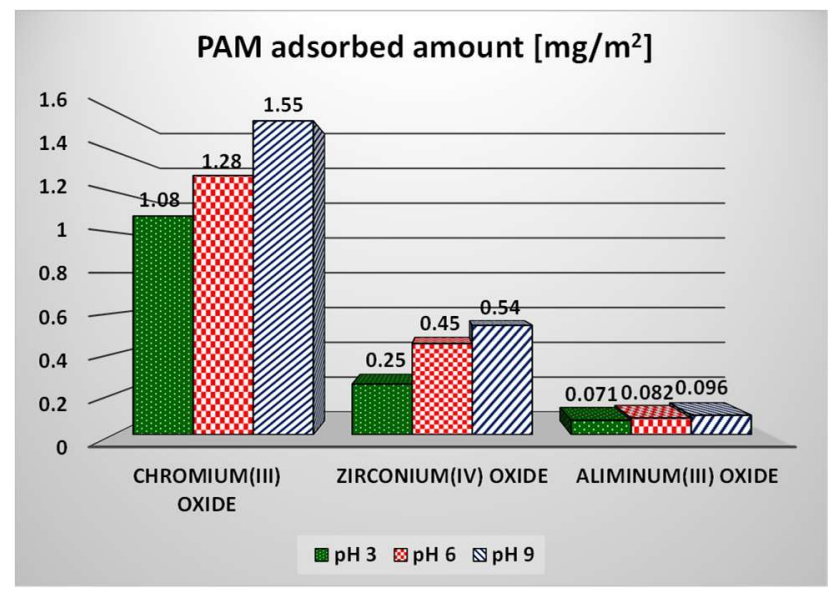

b

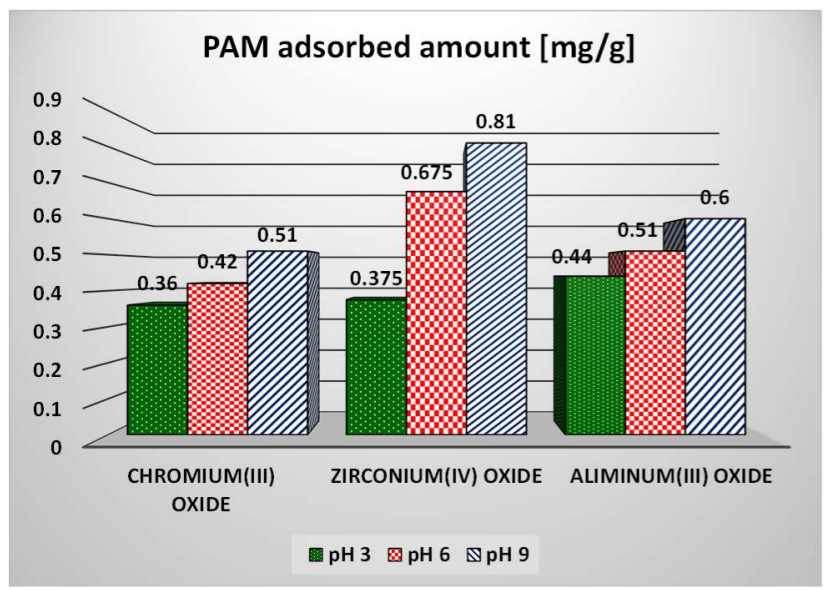

Figure 4. Adsorbed amounts of cationic PAM on the surfaces of examined metal oxides at pH 3, 6 and 9. 
The analysis of the data presented in Fig. 4 indicated that adsorption of cationic polyacrylamide increases with the $\mathrm{pH}$ increase for all examined metal oxides. Moreover, adsorbed amounts of the polymer per unit area of the solid is the greatest in the case of chromium(III) oxide (Fig. 4 a). It is probably connected with concentration of different types of solid hydroxyl groups on the unit of solid surface area (Chibowski and Wiśniewska 2001). In the case of $\mathrm{Cr} 2 \mathrm{O} 3$ the concentration of these groups must be the highest and the polymer adsorption is the greatest. Due to the fact that $\mathrm{Cr} 2 \mathrm{O} 3$ is characterized by the smallest specific surface area the adsorbed amounts of the polymer per unit weight of the solid is the smallest (Fig. 4 b), but comparable with those obtained for $\mathrm{Al} 2 \mathrm{O} 3$ (with the highest specific surface area). This proves the high adsorption affinity of the ionic polyacrylamide to the surface of chromium (III) oxide compared to other examined adsorbents.

The PAM adsorption changes with the solution $\mathrm{pH}$ increase is the result of changes in both the solid surface charge and ionization of the PAM carboxyl groups with the $\mathrm{pH}$ rise. The total surface charge of the solid assumes zero value (point of zero charge - pzc) at specific $\mathrm{pH}$ for each system containing metal oxide. The determined values of pHpzc points for all examined systems are presented in Fig. 5. Below $\mathrm{pH}_{\mathrm{pzc}}$ the solid surface is positively charged and above this value, the solid surface assumes negative charge. Thus, the most favorable electrostatic conditions for adsorption of cationic polymer on the surface of given metal oxide is above its $\mathrm{pH}_{\mathrm{pzc}}$ value.

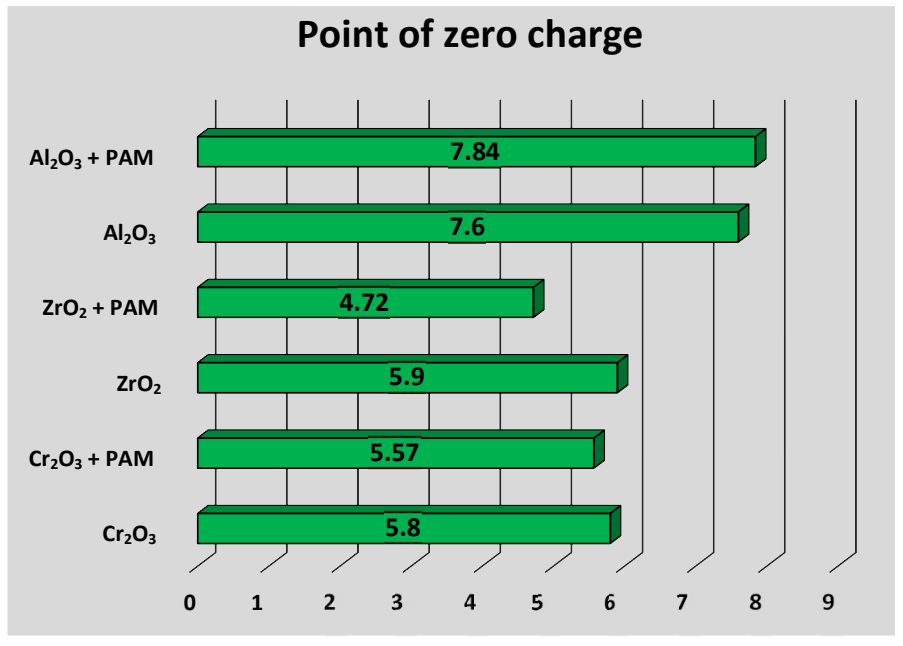

Figure 5. $\mathrm{pH}_{\mathrm{pzc}}$ values of the metal oxide systems without and with cationic polyacrylamide.

As can be seen in Fig. 5 the points of zero charge for $\mathrm{Cr}_{2} \mathrm{O}_{3}, \mathrm{ZrO}_{2}$ and $\mathrm{Al}_{2} \mathrm{O}_{3}$ oxides are equal to 5.8; 5.9 and 7.6, respectively. For this reason, the greatest adsorption of positively charged PAM macromolecules is observed at $\mathrm{pH} 9$ at which the electrostatic attractions between adsorbate and adsorbent takes place. The polyacrylamide adsorption has the lowest level at $\mathrm{pH}$ 3 due to the repulsion between the totally ionized PAM macromolecules and the positively charged surface of the solid. The polymer binding with the metal oxide surface undergoes through the hydrogen bridges under these disadvantageous conditions. Although the charged active solid sites can contribute to formation of these bonds, the neutral ones are mainly responsible for it. This results from the fact that $\equiv \mathrm{MeOH}^{0}$ surface groups are much more numerous than $\equiv \mathrm{MeOH}_{2}{ }^{+}$and $\equiv \mathrm{MeO}^{-}$ones (Chibowski and Wiśniewska 2001). 
Very important parameter related to solid suspension stability is electrokinetic potential zeta. The specific $\mathrm{pH}$ value at which potential zeta of solid particles is equal to zero is called isoelectric point (iep). As can be seen in Fig. 6, the isoelectric points of metal oxides without the polymer are located at $\mathrm{pH}$ values $6,6.4$ and 8.4 for $\mathrm{Cr}_{2} \mathrm{O}_{3}, \mathrm{ZrO}_{2}$ and $\mathrm{Al}_{2} \mathrm{O}_{3}$, respectively. Some differences between the $\mathrm{pH}_{\mathrm{pzc}}$ and $\mathrm{pH}_{\text {iep }}$ values of applied oxides are a result of overlapping of the electrical double layers formed in the pores present in the applied solids structure (Skwarek 2015).

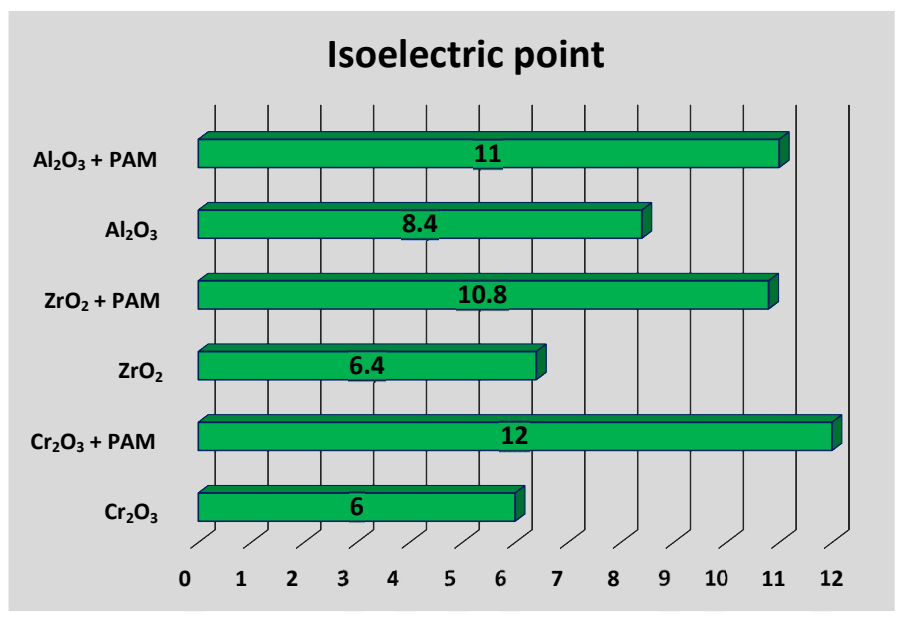

Figure 6. $\mathrm{pH}_{\mathrm{iep}}$ values of the metal oxide systems without and with cationic polyacrylamide.

The presence of cationic polymer layer around the solid particles results in a significant increase of the zeta potential values and the considerable shift of the $\mathrm{pH}_{\text {iep }}$ towards the higher $\mathrm{pH}$ values. The main reason for zeta potential increase in the cationic polyacrylamide presence is the occurrence of positively charged functional groups of the adsorbed polymer macromolecules in the area of slipping planes around the solid particles (Wiśniewska et al. 2016). These groups belong to the polymeric segments located in the loop and tail structures of the adsorbed macromolecules and are not directly bound with the solid surface. They are present in large quantities in the border of the stiff and diffusion parts of the electrical double layers formed on the solid particle surfaces. As a result, such great shift of $\mathrm{pH}_{\text {iep }}$ values for systems with PAM in comparison to the system without PAM is observed.

Taking adsorption and electrokinetic data into consideration the most probable mechanism of solid suspension stability in the cationic polyacrylamide presence can be proposed. The ionic PAM addition at $\mathrm{pH} 6$ causes considerable improvement of chromium(III) oxide and zirconium(IV) oxide systems stability. These suspensions without polymer are unstable at $\mathrm{pH} 6$ due to the fact that such $\mathrm{pH}$ value is very close to points of zero charge and isoelectric points obtained for $\mathrm{Cr}_{2} \mathrm{O}_{3}$ and $\mathrm{ZrO}_{2}$ (Figs 5 and 6). The adsorption of completely ionized polymer chains on the solid surface at $\mathrm{pH} 6$ results in appearance of electrosteric repulsion of PAM adsorption layers covered metal oxide particles. The adsorbed polymeric layers prevent the aggregation of solid particles not only due to the steric hindrance presence (PAM macromolecules) and also electrostatic repulsion coming from positively charged groups of the polymer. In the case of $\mathrm{Al}_{2} \mathrm{O}_{3}$ the polymer addition at $\mathrm{pH} 6$ causes insignificant improvement of solid suspension stability. The alumina system without polymer is relatively stable in comparison to other examined oxides. Under such conditions bare $\mathrm{Al}_{2} \mathrm{O}_{3}$ particles are positively charged and repulse each other preventing their rapid aggregation. The polymer 
adsorption layer presence makes connection of solid particles even more difficult (for electrosteric reasons).

\section{CONCLUSIONS}

Presented results indicated that high-molecular cationic polyacrylamide, commonly referred to as a polymeric flocculant, can also act as effective stabilizer of aqueous suspensions of metal oxide particles. At specific solution $\mathrm{pH}$ value $(\mathrm{pH} 6)$ and PAM concentration (100 ppm) it causes considerable improvement of chromium(III) oxide and zirconium(IV) oxide suspensions stability. The total ionization of functional groups of adsorbed macromolecules results in electrostetic repulsion between solid particles covered with polymeric layers. Moreover, it was shown that ionic polymer adsorption changes considerably structure of electrical double layer formed at the solid-liquid interface which is reflected in changes of the surface charge density and zeta potential of metal oxide particles dispersed in aqueous solution. 


\section{REFERENCES}

AMUDA, O.S., AMOO, I.A., IPINMOROTI, K.O., AJAYI, O.O. 2006, Coagulation/flocculation process in the removal of trace metals present in industrial wastewater. Journal of Applied Sciences and Environmental Management, 10: 159-162.

BARAKAT, M.A. 2011, New trends in removing heavy metals from industrial wastewater. Arabian Journal of Chemistry, 4: 361-377.

CHIBOWSKI, S., WIŚNIEWSKA, M. 2001, Study of the adsorption mechanism and the structure of adsorbed layers of polyelectrolyte at metal oxide-solution interface. Adsorption Science \& Technology, 19: 409-421.

ENTRY, J.A., SOJKA, R.E. 2000, The efficacy of polyacrylamide and related compounds to remove microorganisms and nutrients from animal wastewater. Journal of Environmental Quality, 29: 1905-1914.

HUNTER, R.J. 1981, Zeta Potential in Colloid Science. Academic Press, New York.

JANUSZ, W. 1999, Electrical double layer at the metal oxide/electrolyte interface in interfacial forces and fields: theory and applications. Surfactant Science Vol. 85, M. Dekker, New York.

JIANG, Z., ZHU, J. 2014, Cationic polyacrylamide: synthesis and application in sludge dewatering treatment. Asian Journal of Chemistry, 26: 629-633.

SCOGGINS, M.W., MILLER, J.W. 1975, Spectrophotometric determination of water soluble organic amides. Analytical Chemistry, 47:152-154.

SIMPSON, D.J., THILAGAM, A., CAVAllARO, G.P., KAPLUN, K., GERSON, A.R. 2011, $\mathrm{SiO}_{2}$ coated pure and doped titania pigments: low temperature CVD deposition and quantum chemical study. Physical Chemistry Chemical Physics, 13: 21132-21138.

SKWAREK, E. 2015, Thermal analysis of hydroxyapatite with adsorbed oxalic acid. Journal of Thermal Analysis and Calorimetry, 122: 33-45.

SNABRE, P., MILLS, P. 1994, Settling of the suspension of hard spheres. Europhysical Letters, 25: 651-656.

SOJKA, R.E., BJORNEBERG, D. L., ENTRY, J. A., LENTZ, R. D., ORTS, W. J. 2007, Polyacrylamide in agriculture and environmental land management. Advances in Agronomy, 92: 75-162.

TERPIŁOWSKI, K., WIŚNIEWSKA, M., ZARKO, V. 2015, Influence of solution pH, supporting electrolyte presence and solid content on the stability of aqueous nanosilica suspension. Journal of Industrial and Engineering Chemistry, 30: 71-76.

VARGAS-REUS, M.A., MEMARZADEH, K., HUANG, J., REN, G.G., ALLAKER, R.P. 2012, Antimicrobial activity of nanoparticulate metal oxides against peri-implantitis pathogens. International Journal of Antimicrobial Agents, 40: 135-139.

WAWRZKIEWICZ, M., WIŚNIEWSKA, M., GUN'KO, V.M., ZARKO, V.I. 2015, Adsorptive removal of acid, reactive and direct dyes from aqueous solutions and wastewater using mixed silica-alumina oxide. Powder Technology, 278: 306-315.

WIŚNIEWSKA, M. 2012, The temperature effect on the adsorption mechanism of polyacrylamide on the silica surface and its stability. Applied Surface Science, 258: 3094-3101. 
WIŚNIEWSKA, M., CHIBOWSKI, S., URBAN T. 2016, Synthetic polyacrylamide as a potential flocculent to remove commercial chromium (III) oxide from aqueous suspension. International Journal of Environmental Science and Technology, 13: 679690.

WIŚNIEWSKA, M., CHIBOWSKI, S., URBAN, T. 2015, Effect of the presence of cationic polyacrylamide on the surface properties of aqueous alumina suspension - stability mechanism. Applied Surface Science, 320:843-851. 